\title{
QUADRILHA JUNINA: REFLEXÕES ENTRE O TRADICIONAL E O HÍBRIDO
}

\author{
Daniel da Rocha SILVA \\ Stael Moura da Paixão FERREIRA
}

\begin{abstract}
RESUMO
Este trabalho tem como objetivo discutir sobre as transformações culturais apresentadas nos grupos folclóricos e a conexão entre as características tradicionais e inovadoras tendo como corpus as quadrilhas juninas. De modo geral, observa-se que as práticas culturais tradicionais das quadrilhas juninas perpassam por inúmeras mudanças que podem ser visualizadas em muitos aspectos. A metodologia consiste em uma pesquisa bibliográfica, visto que a pesquisa surge de material científico já publicado. Como fundamentação teórica, têm-se: Araújo (1973), Silva (2009), Santos (2012), Albuquerque (2013), além de outros que se agregam ao debate. A análise parte da compreensão de que a cultura é dinâmica e se modifica com as heterogeneidades decorrentes de um mundo globalizado.
\end{abstract}

Palavras-chave: Quadrilha Junina. Cultura popular. Tradição. Hibridismo.

\section{SQUARE DANCE: REFLECTIONS BETWEEN THE TRADITIONAL AND THE HYBRID}

\begin{abstract}
This work aims to discuss the cultural transformations presented in the folk groups and the connection between the traditional and innovative characteristics having as corpus the squares dance. In general, it is observed that the traditional cultural practices of the squares dance go through numerous changes that can be seen in many aspects. The methodology consists of a bibliographical research, since the research comes from scientific material already published. As theoretical basis, we have: Araújo (1973), Silva (2009), Santos (2012), Albuquerque (2013), and others that add to this debate. The analysis starts from the understanding that culture is dynamic and changes with the heterogeneities arising from a globalized world.
\end{abstract}

Keywords: Square Dance. Popular culture. Tradition. Hybridism.

\section{CUADRILHA JUNINA: REFLEXIONES ENTRE EL TRADICIONAL Y EL HÍBRIDO}

\section{RESUMEN}

Este trabajo tiene como objetivo discutir sobre las transformaciones culturales presentadas en los grupos folclóricos y la conexión entre las características tradicionales e innovadoras teniendo como corpus las pandillas juninas. En general, se observa que las prácticas culturales tradicionales de las pandillas juninas atravesan innumerables cambios que se pueden ver en muchos aspectos. La metodología consiste en una investigación bibliográfica, ya que la investigación surge de material científico ya publicado. Como base teórica, se tiene: Araújo (1973), Silva (2009), Santos (2012), Albuquerque (2013), además de otros que se agregan al debate. El análisis parte de la comprensión de que la cultura es dinámica y se modifica con las heterogeneidades derivadas de un mundo globalizado.

Palabras clave: Cuadrilla Junina. Cultura popular. Tradición. La hibridación.

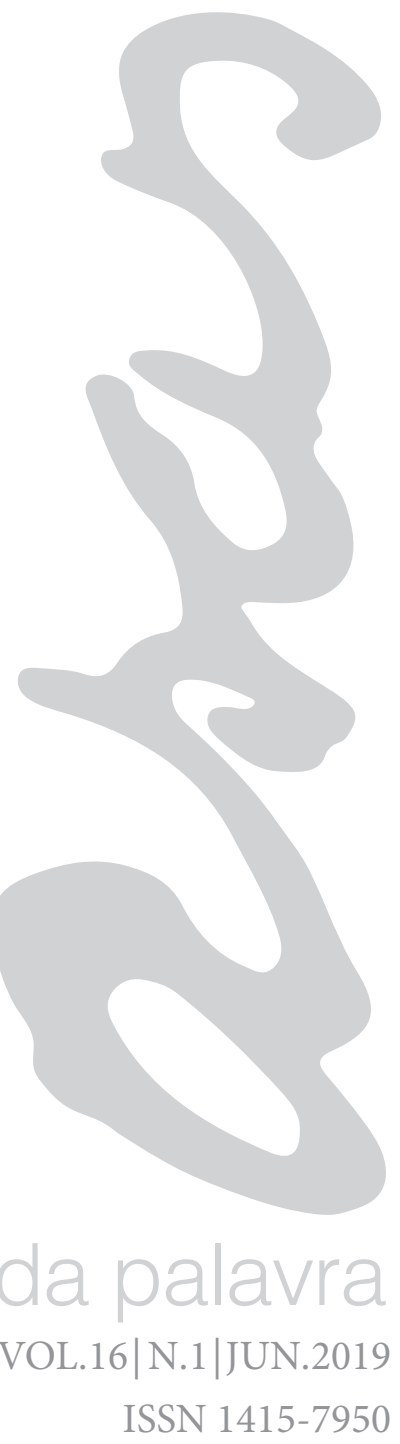




\section{INTRODUÇÃO}

Definir o que é cultura atualmente se tornou uma tarefa árdua para pesquisadores, muito em decorrência da influência contemporânea que se apresenta nos grupos culturais, e em especial nos grupos influenciados pelos meios de comunicação de massa, principalmente com a facilidade e velocidade de informações oriundas da internet, em que é possível acompanhar, em tempo real, quase tudo que acontece em outros meios sociais. Por conta disso, as mudanças advindas das apresentações dos muitos grupos, principalmente os grupos de tradição cultural típica do período das festas juninas, ora encantam, ora incomodam e tornam-se passivas de questionamentos pela sociedade em geral, e simpatizantes que, muitas vezes, assistem com espanto ao "evolucionismo" das práticas culturais tradicionais em suas aparições.

Dito de outro modo, percebe-se que o processo de modernização cultural dos grupos tradicionais juninos, natural do dito "evolucionismo", em que se parte do estado primitivo, aqui representado e registrado pela história dos festejos juninos no Estado de Sergipe, através dos trabalhos clássicos da historiadora Aglaé Fontes em seu livro São João é Coisa Nossa, publicado na década de 1990, que enfatiza o papel das quadrilhas juninas nas manifestações culturais, e que, gradualmente, tornam-se mais civilizados, evoluídos e modernizados por meio de uma integração nacional e que, paralelamente, chamam a atenção da própria sociedade.

As transformações reveladas nos atuais grupos folclóricos juninos podem ser visualizadas em múltiplos aspectos, tanto na dança, quanto na temática, na coreografia, na música, na vestimenta, na alegoria e na evolução. De modo geral, observa-se que, atualmente, boa parte das quadrilhas juninas deixaram de lado a figura do tradicional tabaréu e além de incorporarem outras personagens, como cangaceiros, espantalhos, políticos, divindades, também adotaram inúmeras indumentárias luxuosas. Assim, é perceptível que as práticas culturais tradicionais, ao longo do tempo, sofreram modificações numa dimensão espetacularizada.

$\mathrm{Na}$ verdade, isto pode ser verificado, coincidentemente com a criação dos concursos de quadrilhas da Rede Globo, que, de certo modo, atribuiu a essa modernização um caráter bem especial, considerando que auxiliou no estabelecimento de redes de sociabilidades.

Em 2001, A TV Sergipe, buscando mais uma maneira de divulgar a cultura sergipana, cria um quadro no telejornal "SETV 1a edição", intitulado: São João da Gente, um programa diário que vai ao ar durante o mês de junho e, baseado nesse projeto, surgiu também um concurso de quadrilhas juninas intitulado: Concurso de Quadrilha Junina Levanta Poeira. A partir daí, a "modernização cultural", aqui referida, e que se crê trazida pela TV Sergipe, de certa forma, influenciou o progresso, desenvolvimento e enriquecimento cultural junino no estado, vinculando a modernização a um desenvolvimento estilizado, num reflexo de uma associação entre o tradicional e a inovação, contribuindo para reconstrução de uma identidade junina.

Convém salientar que segundo MARTÍN-BARBERO \& REY (2001), a televisão nacional representou nos países da América Latina um excelente mecanismo de modernização, considerando que, por meio de imagens, "a representação da modernidade se faz cotidianamente acessível às grandes maiorias" (MARTÍN-BARBERO; REY, 2001, p. 41). Nesse sentido, podese dizer que o Concurso de Quadrilhas Juninas Levanta Poeira acabou por influenciar as quadrilhas que mantinham algum vínculo tanto com a FEQUAJUSE (Federação das quadrilhas juninas de Sergipe), quanto às ligadas à LIQUAJUSE (Liga de Quadrilhas Juninas Sergipanas), pois, no intuito de se adequarem para representar Sergipe no Concurso de Quadrilhas Juninas da Globo Nordeste, os grupos partindo em busca de inovação, acabaram por 
inconteste que se consolidava.

Por outro lado, advindas desse desejado processo de modernização surgem, conjuntamente, uma admiração pelo "novo" e uma inquietação marcada pela interpenetração do "diferente". Assim, grande parte da população dualizada nesses processos abstratos entre o encantamento pela evolução e exibição "do luxo" e a manutenção do dito tradicional, acaba por criar uma dificuldade na definição do intitulado "progresso cultural". Todavia, ciente da associação entre a cultura e o tradicional, de forma que o segundo termo se remete ao primeiro, evidenciam-se os seguintes questionamentos: "Até que ponto se perde em tradição quando se acompanha o processo de modernização, isto é, a evolução e a mistura entre culturas, que parece ser inerente?"; "A cultura popular é, necessariamente, tradicional ritualística ou pode ser renovada?" e, por fim, "A evolução dos grupos culturais juninos atraem ou os afastam da sua comunidade?".

A partir desses questionamentos, iniciamos algumas reflexões e a primeira seria analisar a realidade geográfica brasileira. Em um país de dimensões continentais e formação histórica e cultural de povos tão ampla, fica notório a imensa heterogeneidade cultural que nos caracteriza enquanto povo. Desse modo, na obra Cultura popular brasileira, Araújo (1973, p. 9) chama a atenção para o fato de que "procuramos dividir o Brasil em áreas culturais, para que pudéssemos localizar no espaço os fenômenos da cultura, isto é, do conjunto da tradição social". A partir de então, tem-se como corpus para análise o trabalho feito pelas quadrilhas juninas, principalmente às que se situam no estado de Sergipe, comparando-as umas com as outras e com os demais grupos culturais juninos existentes no país, como as escolas de samba cariocas.

Tal pesquisa se justifica pela necessidade de abordagens sobre essa temática em meio acadêmico e científico, para que não continuem restritas somente aos meios de comunicação e/ou às associações de atores e agentes populares envolvidos. Dessa maneira, e por ser uma questão importante para a sociedade, precisamos de mais discussões acerca dos movimentos juninos, tradicionais, pelo tempo de sua prática, mas modernos em suas novas formas de apresentação.

Com isso, o objetivo geral deste trabalho é discutir acerca, e ainda, sobre o que é cultura, por se tratar de um conceito inacabado; além de apresentar a quadrilha junina atual como um movimento influenciado pela contemporaneidade, e debater sobre tradição e hibridismo, no que tange às mudanças vistas nas apresentações das quadrilhas juninas.

A metodologia utilizada nesse artigo consiste em uma pesquisa qualitativa de cunho bibliográfico, que, conforme Prodanov e Freitas (2013, p. 54), se dar "[...] quando elaborada a partir de material já publicado [...]", e que servirá de base para a construção textual. A fundamentação teórica baseia-se principalmente em Araújo (1973), que traz um estudo sobre os movimentos culturais do Brasil; Silva (2009), com um estudo acerca dos quadrilheiros de um grupo sergipano; Santos (2012), acerca da relação entre cultura popular e quadrilha junina; Albuquerque (2013), sobre as mudanças apresentadas pelas quadrilhas juninas.

Desta forma, este estudo se desenvolve apresentando as quadrilhas juninas, enquanto construtoras de movimentos representativos, com capacidade de se caracterizar, tanto tradicionalmente, como patrimônio imaterial inserido num processo de manutenção ritualística e estética, quanto modificadas pela modernidade de forma avassaladora.

\section{CULTURA: TRADIÇÃO VS. HIBRIDISMO}

Como há discordâncias entre outros conceitos referentes às ciências humanas, a exemplo da definição de "identidade" que é vista pela Sociologia, 
Antropologia e até mesmo a Psicologia, sempre com conceituações diferentes, não é diferente quando tentamos definir "o que é cultura?".

É sabido que o termo "cultura" foi utilizado pela primeira vez por Edward Burnett Tylor, em 1877, “[...] para referir-se a todos os produtos comportamentais, espirituais e materiais da vida social humana [...]" (MINTZ, 2009, p. 224). Nesse sentido,

Define-se cultura como uma propriedade humana impar, baseada em
uma forma simbólica, 'relacionada ao tempo', de comunicaçâo, vida
social, e a qualidade cumulativa de interação humana, permitindo que
as ideias, a tecnologia e a cultura material se "empilhem" no interior
dos grupos humanos. (MINTZ, 2009, p. 223)

Com isso, entende-se por cultura a união de características encontradas em uma determinada comunidade, que se encadeiam com outras em um processo continuum de evolução, como bem afirma Silva (2018, p. 18): "Assim, a cultura relaciona-se com toda e qualquer manifestação artística social apresentada por um grupo", embora, conforme o mesmo autor,

\section{[...] sempre nos remete a especificidades locais, portanto, através de grupos, com uma procedencia dotada de antiguidade, em alguns casos, algo primitivo. Essa sensação de "coisa antiga" é trazida em decor- rência da necessidade de explicação do surgimento de grupos cultu- rais. (SILVA, 2018, p. 18)}

Assim, e por esta aglomeração de significados que envolvem a cultura, pode-se defini-la como uma grande área que se preenche de diversas "micro áreas", inclusive a noção de hibridismo. Alguns pesquisadores, como Nestor Garcia Canclini (2011), já trabalham com essa união de palavras, "culturas híbridas", que intitula uma das principais obras desse autor, como um movimento pertencente ao momento atual.

Albuquerque (2013, p. 22, apud Canclini 2011), diz que hibridização consiste em um "[...] processo sociocultural que pode existir de forma separada, combina-se com outras culturas para gerar novas estruturas, os novos povos trazem suas tradições que contribuem no contexto cultural da população local"; ou seja, faz parte de um processo em movimento constante, portanto, mutável. Essas mudanças são ativas e estão sempre presentes na sociedade, o que o torna concomitante à definição apresentada por Mintz (2009). Com isso, nota-se que há um encadeamento entre termos, esses, cada um com seus significados, e ambos acabam por significar o que é cultura. Dessa maneira, há uma aglomeração em ambos os sentidos, quer na explicação da palavra como também na prática desenvolvida na sociedade.

Assim, neste estudo, apresentaremos a cultura como um conceito inacabado, haja vista as inúmeras discussões e divergências acerca do tema. Nesse sentido, pode-se, aqui, entender a definição de cultura como dualidade, a partir do momento em que se apresenta através do tradicional e do hibridismo, enquanto termos opostos, embora interligados para explicar esta questão, isto é, quando ouvimos a palavra "cultura", subjaz, no imaginário, essas palavras, que, na sociedade, dialogam entre si. Assim, a cultura se constitui como uma união que nos faz lembrar de acontecimentos, ou seja, não significa uma unidade, não é homogênea, não é única, não é imutável. Portanto, para entendê-la, faz-se necessário a compreensão de outros conceitos que atuam (re) significando o seu espaço.

Para o senso comum, a tradição é algo que não muda, ou não deveria mudar. No entanto, estudiosos, como Santos (2012), entendem que a tradição, enquanto processo, também sofre mudanças. Nisso,

VOL. 16 | N.1 | JUN. 2019 ISSN 1415-7950 
características cristalizadas sem que apresente nenhuma alteração com o passar do tempo, pelo contrário, ela só o é pela instauração da coerência entre a tradição e o contexto no qual vive a sociedade. (SANTOS, 2012, p. 6)

Por esse prisma, tudo se modifica, porque considera que a mudança parte do maior agente social, o povo, em constante mutação. Então, por que o próprio povo questiona as mudanças se essas partem dele mesmo? Entende-se, que para o senso comum, o povo, há uma divisão entre as culturas, e essas não se misturam, até pelo fato de se relativizar a cultura como característica definidora de uma região, de quem nasceu e cresceu nela, além de ser associada à classe social do sujeito. Nesse sentido, há uma resistência e uma "tentativa de apagamento" em relação ao "novo", que adentra na cultura local, trazida pelas relações entre os povos, tanto de forma pessoal, quanto nas relações pelas mídias digitais. Atualmente, a rede mundial de computadores, através da internet, consolida-se como o principal agente de imigração entre os conhecimentos culturais. Essa relação de mutação fica ainda mais evidente com o pensamento de Giddens (2000): A ideia de que a tradição é impermeável à mudança é um mito. As tradições evoluem ao longo do tempo, mas podem também ser alteradas ou transformadas de maneira bastante repentina. [...] A persistência ao longo do tempo não é a característica chave que define a tradição, ou seu primo mais difuso, o costume. As características distintivas da tradição são o ritual e a repetição. As tradições são sempre propriedades de grupos, comunidades ou coletividades. Indivíduos podem seguir tradições ou costumes, mas as tradições não são uma característica do comportamento individual do modo como os hábitos o são (Giddens, 2000, p. 51-52).

A tradição constitui, conforme o autor, no ritual e na repetição. Desse modo, entende-se como um fenômeno que permanece no tempo através de sua prática, muito mais em decorrência da repetição. Logo, as mudanças contemporâneas não interferem na prática do movimento cultural enquanto tal, enquanto manifestação, enquanto símbolo e significado; apenas interferem em seus modos periféricos de realização, ou seja, no vestuário, no acrescentamento de ritmos musicais, dentre outros. E é nesses que se encontram a discordância do povo.

Desta forma, o tradicional nos remete também ao popular. O Dicionário Aurélio define o que é popular, em sua terceira acepção, como algo "Vulgar, trivial" (FERREIRA, 2010, p. 598). Por esse prisma, compreende-se essa dificuldade de aceitação das novidades encontradas nos grupos culturais, principalmente àqueles com maior tempo de existência, como é o fato das quadrilhas juninas, visto que, como bem afirma Santos (2012, p. 2), “[...] o popular é comumente associado ao atraso, que não tem seu lugar nas sociedades modernas por radicar-se nas amarras tradicionais". Ainda, nesse conceito, "tradição" subjaz algo velho, ou seja, em oposição ao novo, o que também acaba por classificar a cultura neste foco.

A partir de então há outra oposição, o popular da elite. A elite constituída de tudo o que há de moderno, e o popular de tudo o que resta do passado, em que devem ser vistos separadamente, ou seja, um não pode se misturar ao outro, e em que o moderno, da elite, é evolução; e o passado, popular, é retrógrado. Portanto, um emaranhado criterioso que faz da cultura um movimento complexo, visto as suas considerações por diversos pontos de vista, como, inclusive, o antropológico.

É sabido que o significado da palavra "hibridismo" está ligado ao agrupamento de palavras, ou seja, à mistura entre vocábulos. Esse fenômeno proporciona o surgimento de palavras novas. Portanto, 
de línguas distintas: alcaloide-Álcali (árabe) + óide (grego)

Característica daquilo que provém de naturezas distintas.

Falta de normalidade; ausência de proporção ou simetria; hibridez ${ }^{1}$.

Observa-se, através do exemplo citado, que pode ser uma mistura proveniente de elementos totalmente diferentes e distantes entre suas origens. Assim também se configura quando se fala em heterogeneidade cultural, desse modo, o processo de hibridização é marcado por elementos diversos, portanto, resulta também em elementos diversificados, e nunca por uma homogeneização, não há uma cultura homogênea no sentido de única, de intransponível, de imutável. Assim sendo, fica notório essas variações nas apresentações das quadrilhas juninas, que vão do vestuário à abertura da apresentação (outra inovação), situação que provém muito por conta do contato entre as pessoas de lugares diferentes, além de outros fatores.

Assim, mesmo ciente de que as "tradições juninas" são ritualizadas para servir a própria legitimação, é possível considerar que o contato social é também um grande agente modificador dos grupos culturais, visto que é visto como inovador e envolve tudo o que se encontra na sociedade. Por esse ponto de vista, o evolucionismo fica inerente em qualquer situação, até pela necessidade de interação entre as comunidades pertencentes à sociedade. Com isso, acompanhar as mudanças contemporâneas é uma questão de inclusão que se baseia em duas possibilidades: ou muda ou se isola.

\title{
QUADRILHAS JUNINAS: DATRADIÇÃO À EVOLUÇÃO, ASPECTOS RELEVANTES
}

É sabido que a quadrilha junina tem origem europeia, embora o senso comum a conclame como de origem nordestina, até pela caracterização típica que obteve na região e por se tornar evento indispensável no mês de junho, época das comemorações do São João, em que envolve um sentimento ainda maior do povo nordestino, a fé. Assim:

\begin{abstract}
Etimologicamente, a palavra "quadrilha" é proveniente do francês quadrille, do italiano quadriglia ou squadro e do espanhol cuadrilhas, que remetem à disposição de pares em forma de quadrado. A quadrilha surgiu em Paris no século XVIII tendo com o precursor Philip Musard [...] (ALBUQUERQUE, 2013, p. 44)
\end{abstract}

1 Hibridismo. Disponível em: $<$ https://www.dicio.com.br/ hibridismo/> Acesso em: 19 dez. 2018.

2 Com o objetivo de preservar esta tradição, um grupo de franceses fundou uma associação com a pretenção de reunir em torno de costumes sobre a dança, trajes e história correspondente à "Vida de Quadrilha" no período de 1848 a 1918. O grupo realiza eventos onde os dançarinos se caracterizam com vestimentas da época: os homens usavam fraque ou smoking, um traje de cerimônia que se usa em eventos formais, e as mulheres com vestidos longos, social, com modelos característicos da época. (ALBUQUERQUE, 2013, p. 45) por volta dos séculos XIII e XIV. O contato cultural entre a França e a Inglaterra, durante a guerra dos Cem Anos, fez a França adotar a dança, que, levada para os palácios, tornou-se nobre, vindo a espalhar-se por toda a Europa, integrando as festas da nobreza. (SILVA, 2009, p. 1) então, as quadrilhas juninas já são hibridizadas. No entanto, acostumamos a vê-las com características típicas que nos remetem à ruralidade, especificidade que também se relaciona à sua derivação, pois para Giffoni (1964), a quadrilha deriva da Contredanse Française ${ }^{2}$; que, conforme Castagna (2003 apud Albuquerque 2013, p. 45), "[...] é uma adaptação da dança inglesa "Country dance', que significa dança campestre". Portanto, essa relação ao "caipirês" (no sentido de interior) advém dos primórdios, e nesse sentido, entende-se a primazia popular pela manutenção dessa característica inicial, embora a mesma tenha se iniciado por grupos de danças formados por pessoas da alta sociedade.

Por causa da familiaridade com os ingleses, há pesquisadores que atribuem a origem da quadrilha junina como proveniente da Inglaterra, como afirma Silva: 
No Brasil, esse movimento dançante foi trazido pela Corte Imperial Portuguesa, basicamente no século XIX, como bem afirma Giffoni (1964), porém, os responsáveis por este feitio foram dois franceses, mestres de orquestras, que atendiam à Corte, Milliet e Cavalier, conforme a autora. A partir de então, começaram a se formar grupos de dança com tal característica, e por ser uma novidade, ganhou adeptos e simpatizantes. Com isso, não ficou restrito apenas aos abastados do poder, a dança ganhou espaço também no interior, e foi por lá que se tornou popular, ganhou novos atributos, e não para desde então. Cascudo (1972, p. 746), um dos mais reconhecidos pesquisadores populares, afirma que: "a quadrilha não só se popularizou como dela apareceram várias derivadas no interior. Assim a 'quadrilha caipira', no interior paulista, 'baile sifílito' na Bahia e Goiás, a saruê (deturpação de soirée), no Brasil Central" (grifos do autor), fica visível que apesar dos novos dançantes com costumes diferentes, ainda permanece a influência francesa, principalmente quanto às palavras utilizadas para a denominação dos passos da dança (por exemplo, "anarriê") e dos próprios grupos aderentes.

Com a interiorização, as quadrilhas foram apresentando ainda mais mudanças, pois "Desceu as escadas dos palácios e hoje vive apenas refugiada no hinterland brasileiro, aparecendo por ocasião das festas juninas" (ARAÚJO, 1973, p. 72), relato que configura a época do autor, porque nos dias atuais, as quadrilhas juninas já não são movimentos exclusivos dos interiores, pois estão presentes nas grandes cidades, inclusive nas capitais do país. Desse modo, subjaz que nas cidades da época, a dança era praticada apenas pelo alto escalão, não se envolvendo com o subúrbio, conforme pontua Alceu Maynard Araújo (1973), descrevendo como aconteciam as apresentações das quadrilhas:

No começo deste século era infalivelmente encontrada nos bailes de roça onde a marcação conservava algo da terminologia francesa com os mais deliciosos estropiamentos dos vocábulos originários. Ela aí nada tinha de protocolar como nos palácios e podemos afirmar, até 1930 era a parte mais deliciosa dos bailes populares das cidades interioranas ou das fazendas cafeicultoras paulistas, dançada nas tulhas ou terreiros de café ao som de sanfonas, findando no mais confuso galope. Já estava, nesta época, em decadência o velho hábito de declamar versos, quadrinhas com intenção amorosa, cheias de lirismo, nos intervalos das partes da quadrilha, no miudinho, antes da quinta parte, considerada a mais importante. O dizer quadrinhas dava aos enamorados oportunidade de fazerem suas declarações de amor. Na hora do miudinho muitos pais ficavam de "orelha em pé" para ver qual era o moço que estava "arrastando asas" pela sua filha. (ARAÚJO, 1973, p. 72)

Em comparação às apresentações atuais, observam-se inúmeras modificações, mas algumas ramificações desse passado ainda continuam, mesmo que de forma simbólica, como o momento reservado aos "enamorados", que pode ser relacionado ao "passeio na roça" ou ao ritual de "casamento" durante a apresentação da quadrilha.

Percebe-se, então, que o processo de hibridização é constituído desde as origens, a partir do contato entre as danças inglesas e francesas, independentemente de onde literalmente se originou, pois é possível analisar dois fatos quanto a isso: a origem é francesa, mas foi influenciada por um grupo de dança inglês; a origem é inglesa, mas manteve contato com os franceses em um período migratório. Em comum, o contato cultural entre os povos.

No Brasil, em decorrência de sua diversidade, essa hibridização se torna inevitável, e não é um acontecimento apenas desta década. Nesse sentido, as inovações são perceptíveis em todos os prismas, desde a evolução linguística, com o surgimento de novas palavras e a simplificação de léxicos 
franceses, à evolução dos trajes dos dançarinos com muito brilho e cores. $\mathrm{Ou}$ seja,

[...] a quadrilha foi se adaptando aos costumes brasileiros, este fato é constatado em alguns termos, que foram adquirindo característica portuguesa ou surgindo novas criaçoes, por exemplo: 'damas ao centro', 'é mentira', 'olha o túnel', 'olha a chuva', 'passeio'. (ALBUQUERQUE, 2013, p. 45)

Para efeito visual de comparação, nota-se essa ampla discussão nas seguintes imagens:

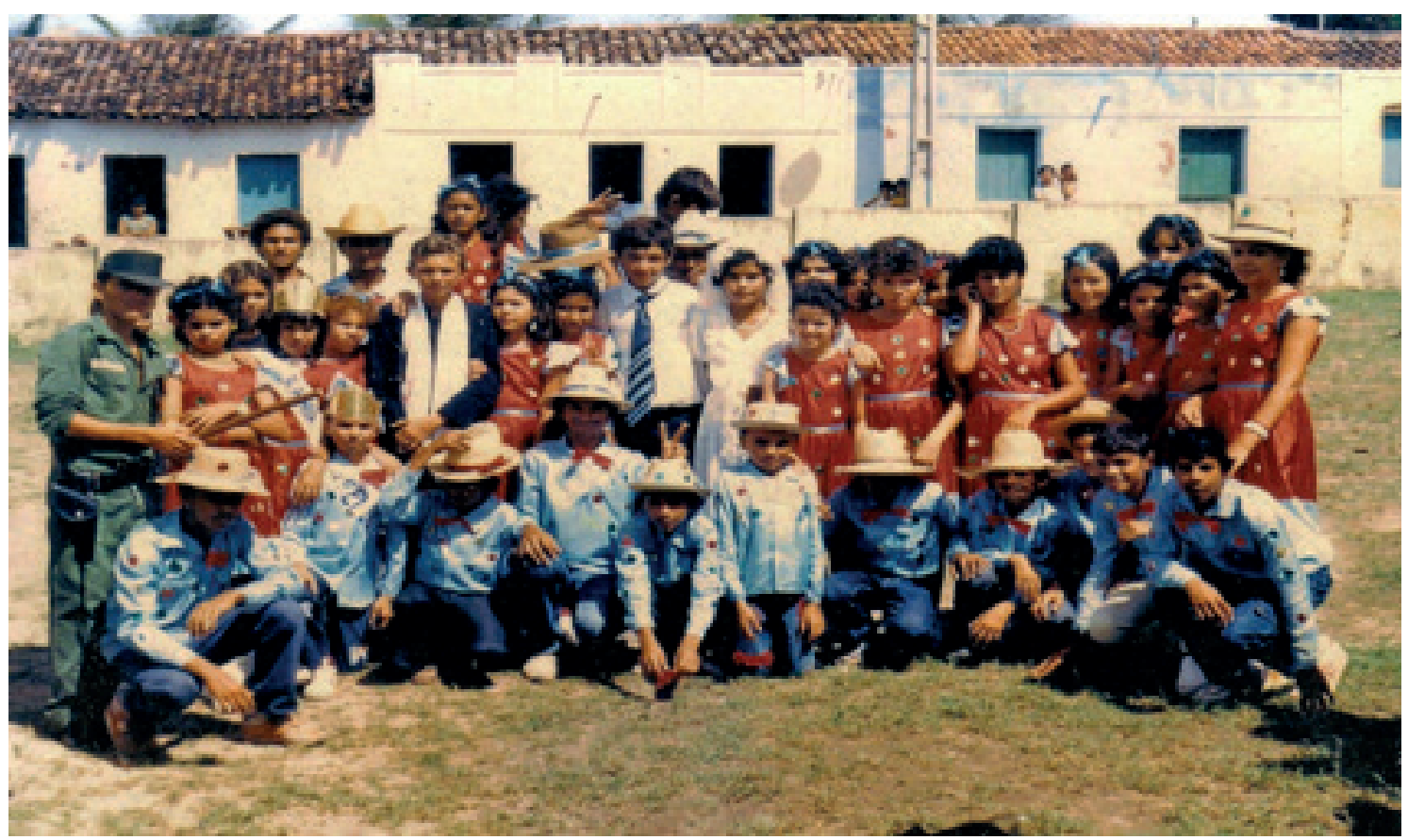

Figura 1: Quadrilha Junina do Rio Grande do Norte, anos 70/80. Disponível em: <https://espiritosantornemfoco.wordpress.com/2013/01/03/espirito-santorn-50-anos-fotos-ii/> Acesso em: 21 dez. 2018.

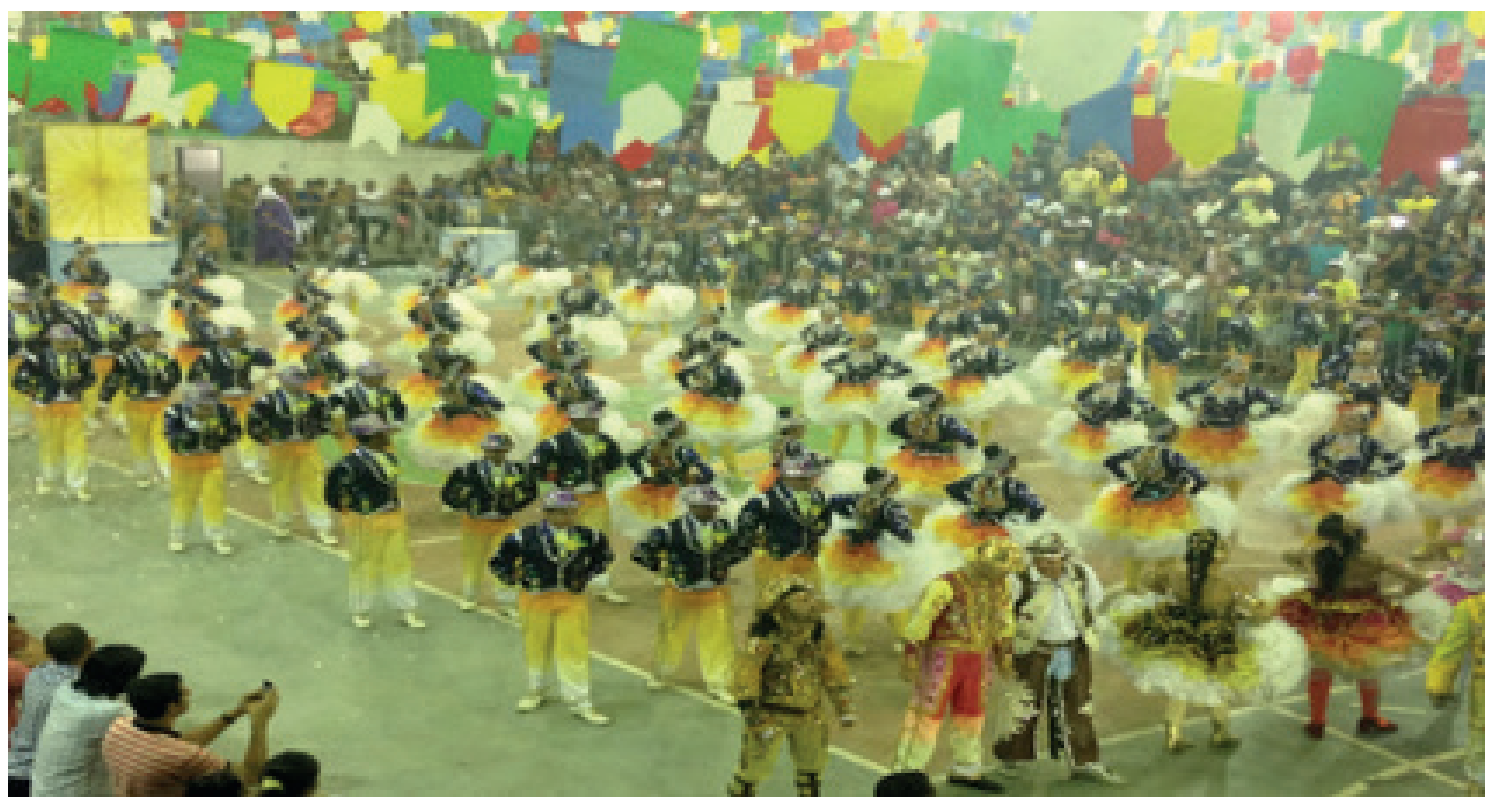

Figura 2: Apresentação da Quadrilha Junina São João - RN, em 2015. Disponível em: <http:// montealegreemdia.blogspot.com/2015/06/ginasio-lotado-na-penultima-noite-de.html> Acesso 
Percebe-se também que há uma enorme diferença nas vestimentas, embora os passos de dança também tenham evoluído diante deste processo, outrora visto como algo natural. A contemporaneidade espalhada pelas mais distantes comunidades dos grandes centros é levada pelos meios de comunicação, tanto a televisão, quanto a internet. E diante do assistir às manifestações culturais retumbantes para o resto do país, a exemplo do desfile das escolas de samba do Rio de Janeiro, acabam por se influenciar, umas com as outras. Esse fenômeno é percebido por conta dessa caracterização estar presente em todos os lugares. Abaixo, a imagem é de uma quadrilha junina da cidade de Tobias Barreto, a cerca de $133 \mathrm{Km}$ de Aracaju, capital do Sergipe.

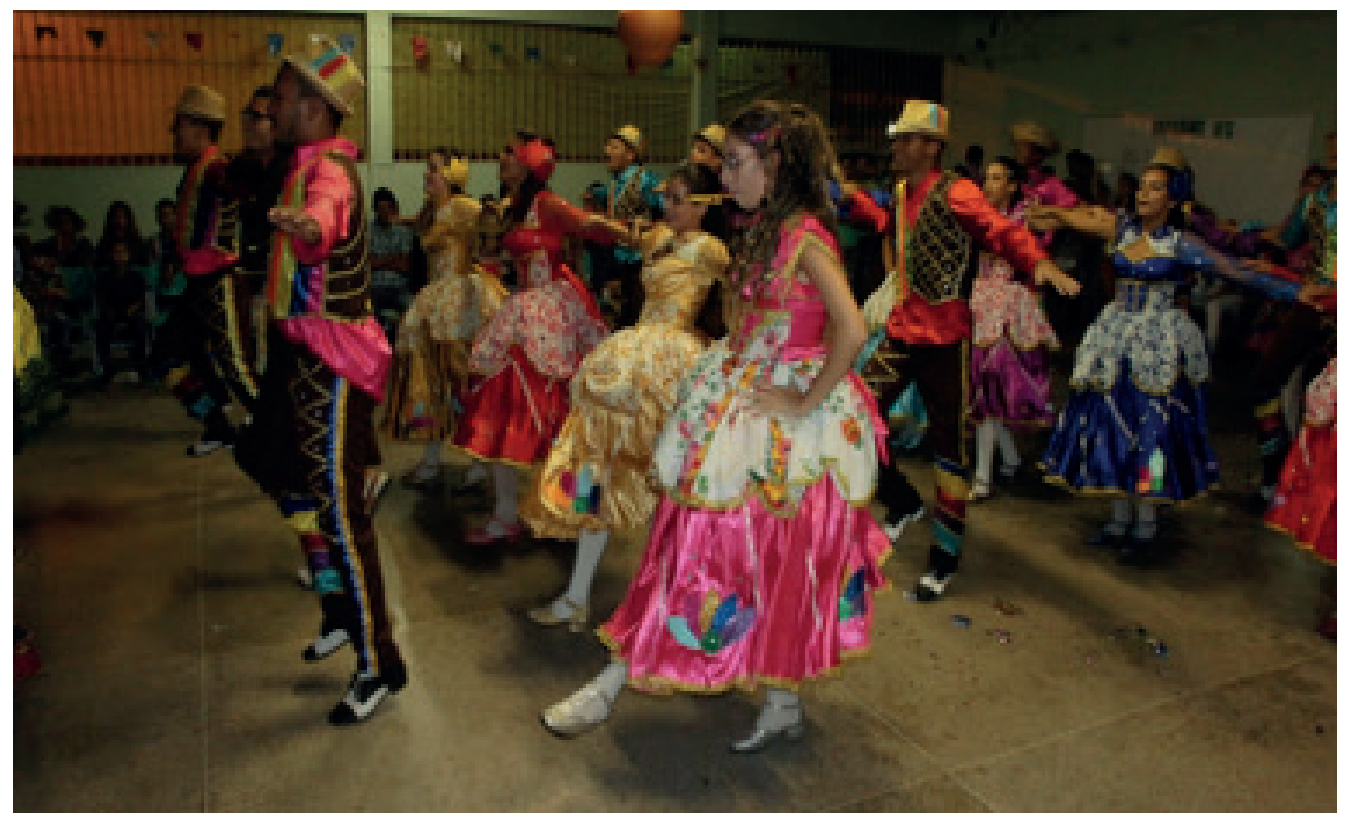

É perceptível que o processo híbrido se faz presente até nas cidades mais distantes das capitais. E como essa hibridização chegou tão longe? Através, principalmente, das mídias de comunicação.

As maiores mudanças são percebidas visualmente no traje dos

Figura 3: Quadrilha Junina Meu Xamego, em apresentação no Instituto Federal de Sergipe, Tobias Barreto, 2017. Fonte: Arquivo pessoal do Autor, 2018. brincantes, no entanto, vão muito além disso. As quadrilhas juninas já não significam apenas um grupo formado entre amigos para diversão, elas contraíram uma característica competitiva. Com isso, surgiram adaptações que os grupos precisam seguir para participação nos famosos concursos pelo país, organizados por associações que os representam e até mesmo pelas emissoras de televisão, tão grande é a apelação popular pelos festivais. Esse acontecimento trouxe regulamentações, critérios de avaliação e premiações para as quadrilhas mais bem notificadas, o que proporciona ainda mais inovações nos conjuntos, visto que os agentes estão sempre em busca de surpreender as bancas julgadoras.

A partir dessa mercantilização, o processo estilístico é considerado como um exagero pelo senso comum, a partir do momento que as quadrilhas juninas têm modificado as temáticas e até seus próprios nomes. Nesse caso, para fins de exemplificação, cita-se o grupo "Artes Cênicas Unidos em Asa Branca", de Aracaju -SE. E a pergunta: por que não "Quadrilha Junina Unidos em Asa Branca?". Convém associar tal fato a um dos requisitos dos concursos, que é a abertura da apresentação da quadrilha, em que uma encenação teatral remete ao tema abordado, esse, outro fator inovador. As quadrilhas juninas escolhem uma abordagem temática para suas apresentações, em que toda a montagem da apresentação, do figurino

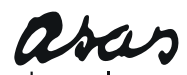

da palavra 
ao repertório musical, deve estar em coerência. Além disso, no contexto atual de inovação junina, em se tratando de artes cênicas, percebemos que os grupos buscam inspiração nas mais diversas áreas. Assim, a influência exercida por outras manifestações culturais se torna inegável a partir das imagens:

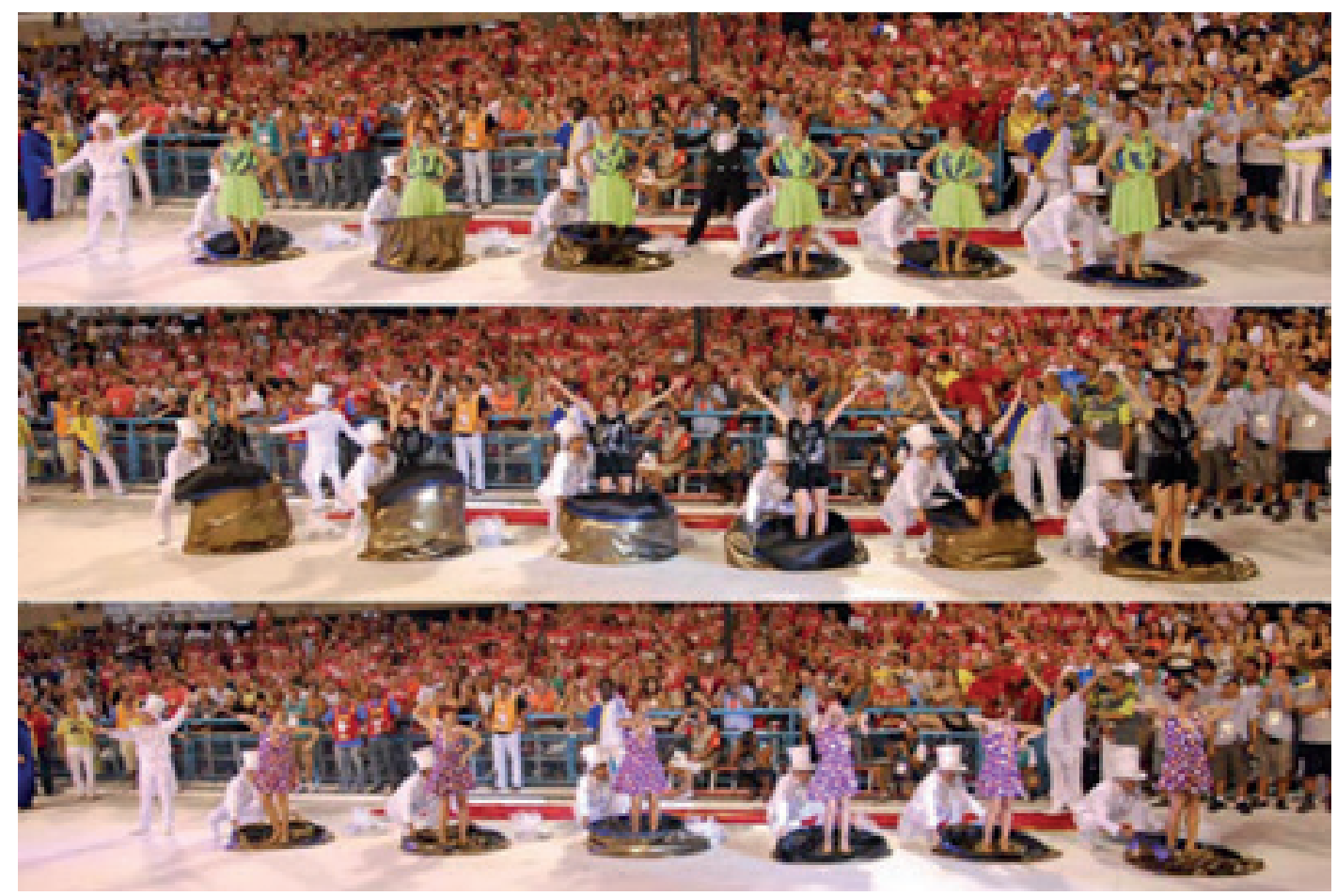

Figura 5: Apresentação da quadrilha junina Artes Cênicas Unidos em Asa Branca, de Aracaju, na final do Concurso "Levanta Poeira", em 2015. Disponível em: <https://www.youtube.com/watch?v=XZQpq4fuyOU> Acesso em: 23 dez. $2018^{3}$.

3 As imagens foram coletadas de vídeo através de Print.

\section{aras}

da palavra

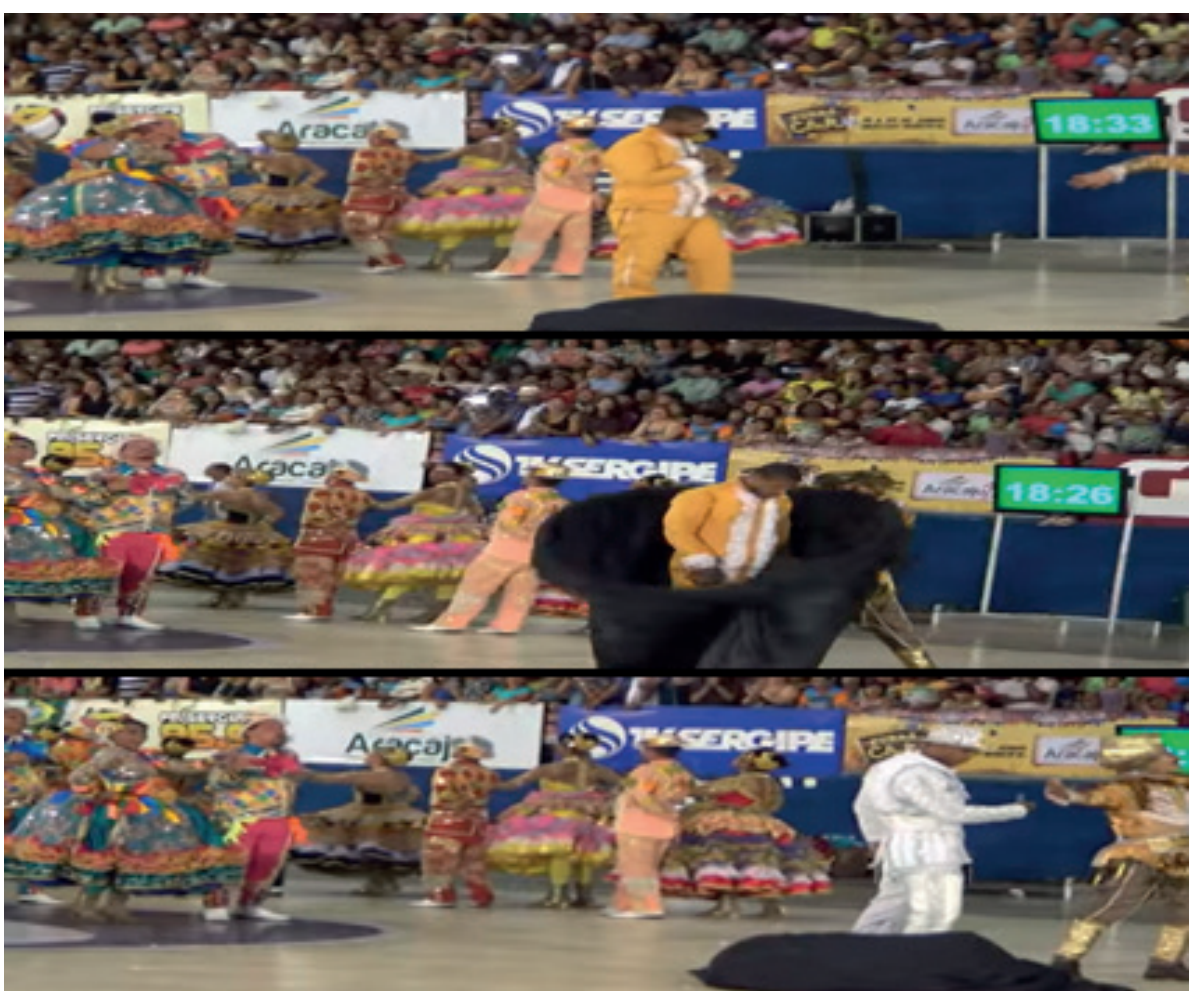

Figura 4: Comissão de frente do Grêmio Recreativo Escola de Samba Unidos da Tijuca, Rio de VOL. 16 | N. 1 | JUN. 2019 Janeiro, 2010. Disponível em: < http://comissaodefrente.blogspot.com/2012/07/nossa-historiaISSN 1415-7950 -unidos-da-tijuca-e-as.html> Acesso em: 17 dez. 2018. 
Observa-se que, na atual busca pela dita inovação, os grupos juninos acabam ultrapassando limites, barreiras, e buscando inspiração em outras áreas, como acontece com o grupo junino supracitado que, inspirado na apresentação da comissão de frente do Grêmio Recreativo Escola de Samba Unidos da Tijuca, no Rio de Janeiro, na Sapucaí em 2010, traz para sua apresentação um truque de ilusionismo que, na verdade "[...] ganhou popularidade no show de talentos norte-americano. A mágica chamada de Quick Change, ou mudança rápida"', um truque que se baseia na sobreposição de roupas.

Destaca-se que o show de talentos norte-americano, estreado em junho de 2006, intitulado American's Got Talent, também conhecido como AGT, é famoso por apresentar inúmeros cantores, dançarinos, humoristas e mágicos de todas as partes do mundo. Trata-se de uma série de televisão estadunidense exibida pela National Broadcasting Company, mais conhecida como NBC, uma companhia de Radiodifusão americana, e parte da série global Britain's Got Talent, criado por Simon Cowell, executivo britânico da BMG do Reino Unido.

Desta forma, o Quick Change, ilusão mágica, que tem sido um dos mais favoritos truques de mágicos passa a fazer parte do contexto das apresentações juninas. O que assevera ainda mais com a hibridização cultural, considerando que o truque importado, foi ovacionado pelo público e pela crítica:

A base do truque está na sobreposição de roupas: a bailarina já está usando todas as roupas que apresenta, o que muda são as formas utilizadas para que sejam reveladas. Trata-se de um processo que usa zíperes, velcros, imãs e ganchos inseridos no vestuário ${ }^{5}$.

Assim, o mesmo truque ilusionista foi utilizado nas duas apresentações, mas como a escola de samba foi pioneira ao mostrá-lo ao público, compreende-se, por isso, que houve uma influência de uma para com a outra cultura.

Ressalta-se que, na escola de samba carioca, como dito, esse efeito visual veio na famosa "Comissão de frente" dos desfiles das agremiações, enquanto que na quadrilha junina sergipana, tal fato aconteceu durante um momento muito esperado pelos telespectadores e jurados, o casamento. Assim, o dançarino, que estava com a vestimenta igual aos demais dançarinos, vestiu sua roupa de noivo em pleno arraial, comumente, mostrado durante o ápice de ambas as apresentações.

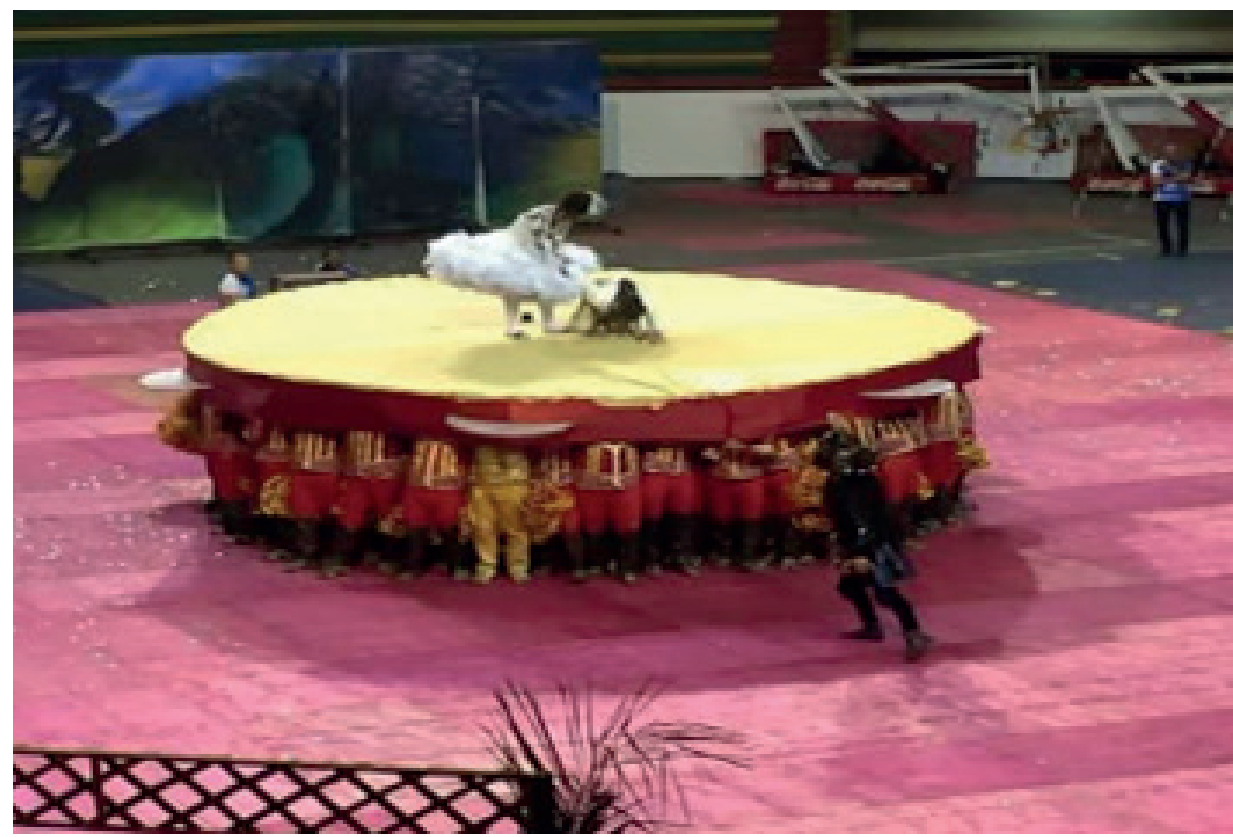

Figura 6: Apresentação da quadrilha junina Artes Cênicas Unidos em Asa Branca, no concurso "Zabumba de Ouro", Aracaju, 2018. Disponível em: $<$ https://www.instagram.com/p/ BjwLE9EHG4E/?utm_source=ig_share_sheet\&igshid $=$ pizg3ppdu7hg> Acesso em: 23 dez. 2018. 
Sabe-se que as manifestações culturais prestam homenagens umas às outras, o que mostra um processo de hibridização aceitável pelos mantedores dessa prática viva e tão essencial para a sociedade. É o que se destaca na próxima imagem:

Após o momento do casamento, há uma homenagem ao "samba de coco" ou simplesmente "coco", como prefere Araújo (1973). O grupo junino o homenageia por ser uma dança praticada no estado de Sergipe, sendo uma das manifestações mais antigas e, por isso, preservada pelo seu povo.

É a dança dos pobres, dos desprovidos da fortuna, daqueles que possuem apenas as mãos para dar ritmo, para suprir a falta do instrumento musical. E este quando existe é membranofônio ou idiofônio. O canto é acompanhado pelo bater de palmas, porém palmas com as mãos encovadas para que a batida seja mais grave, assemelhando-se mesmo ao ruído do quebrar a casca de um coco (Cocos nucifera), tão abundante no E. de Alagoas, donde parece ser originária esta dança afro-ameríndia. (ARAÚJO, 1973, p. 81-82) É sabido que o samba de coco é originário da região nordeste do país, e possui influência africana. Por ter sido praticada pelos mais pobres, considera-se que a mesma era eventualmente dançada nos quilombos e nas senzalas. Assim:

Forma-se a roda de homens e mulheres, e ao centro vai o solista que põe o "argumento", isto é, a melodia e texto. Logo sobressai o refrão cantado pelos demais da roda. Ainda no centro o solista executa requebros e sapateados, passos figurados e ao finalizar faz sua vênia ou reverência. Retira-se, entra outro. (ARAÚJO, 1973, p. 82)

Portanto, percebe-se que o processo de hibridização decorre também entre as manifestações mais antigas, em que algumas estão caindo em esquecimento. Nesse sentido, essa heterogeneidade se torna mais que necessária, no intuito de manter vivas as mais nobres danças representativas do nosso povo.

\section{CONSIDERAÇÕES FINAIS}

As reflexões feitas no presente trabalho têm a intenção de produzir uma quantidade considerável de reflexões, análises e proposições sobre universo formado pelos grupos juninos e suas características atuais, mencionando e considerando a hibridização cultural como algo natural, inegável na contemporaneidade e inerente a todo processo de inovação, vista como um modificador constitutivo às próprias manifestações culturais.

Sabe-se que a invenção ou introdução de novos conceitos, a difusão de conceitos a partir de outras culturas e, mesmo, a descoberta, ou revelação de algo desconhecido são considerados mecanismos básicos de transformação cultura, considerando que a cultura é dinâmica e, enquanto mecanismo adaptativo e acumulativo, sofre grandes transformações, em que alguns elementos se perdem, outros se adicionam, em tempo e velocidades distintos. Com relação às dificuldades e a resistência às mudanças, salientamos que é compreensível, pois para muitos, essa resistência está diretamente relacionada ao grau de compreensão de descontinuidade da cultura. No entanto, os grupos juninos possivelmente encontrarão soluções para ajudar a promover essas mudanças de forma pouco traumática.

Dito isso, ressalta-se que muitos grupos juninos, dentro desse movimento de inovação, são considerados por muitos como "profissionalizados", aos moldes dos diversos referenciais sociais e culturais que se apresentam enquanto fusão, provavelmente, buscando, simplesmente, representar uma clara expressão do mundo em que vivemos atualmente, em que, dificilmente, encontram-se manifestações culturais "puras", no sentido de não sofrerem quaisquer intervenções externas à sua realidade.

Desta forma, os carros alegóricos (típicos das escolas de samba) 
passam a fazer parte das grandes apresentações juninas, desde que o "cenário de abertura" passa a ser um dos requisitos de concursos de quadrilhas, o que facilita a apresentação de grupos ainda mais híbridos.

A partir de então, e pela permanência da essência, enquanto simbologia social, não há espaço para discussões que promovam a dicotomia "certo/errado". Assim, o estilismo apresentado nas quadrilhas juninas dá-se por conta desse intercâmbio cultural, e por se tratar de um país tão misto, isso é imprescindível, se observado por esse ponto de vista.

Assim, considera-se, a partir do que foi mencionado, que as inovações continuarão a ser apresentadas, e surpreenderão ainda mais o público, com elogios e/ou divergências, pois é possível compreender que haverá sempre a junção de elementos de diversas culturas. No entanto, também haverá a permanência de símbolos que demonstram as raízes culturais dos grupos e a preocupação em reviver os tradicionais festejos juninos.

Os conceitos apresentados neste trabalho devem ser compreendidos como elementos que auxiliam no processo de compreensão da reconstrução de identidades e, ao mesmo tempo, manutenção de valores e crenças, visto que as inovações juninas criam ritos particulares e agregam valores com o passar do tempo.

\section{REFERÊNCIAS}

ALBUQUERQUE, Teresa Kátia Alves de. As quadrilhas juninas e suas transformações culturais nos festivais folclóricos em Boa Vista - Roraima (20012011). 2013. 154 f. Dissertação (Mestrado em Sociedade e Cultura na Amazônia) - Universidade Federal do Amazonas, Manaus, 2013. Disponível em: $<$ https://tede. ufam.edu.br/handle/tede/2299> Acesso em: 19 dez. 2018.

ARAÚJO, Alceu Maynard. Cultura popular brasileira. 2a . ed. São Paulo: Melhoramentos, 1973.

ALENCAR, Aglaé D’Ávila Fontes de. São João é coisa nossa. Aracaju. FUNDESC/ Ed. J. Andrade, 1990. (Série Memória viva v. II).

CASCUDO, Luís Câmara. Dicionário do Folclore Brasileiro. $3^{\mathrm{a}}$. ed. Rio de Janeiro: INL, 1972.

CLIC RBS. Como foi a troca de roupas rápida da comissão de frente da Unidos da Tijuca. Disponível em: <http://www.clicrbs.com.br/especial/rs/ carnaval/19,0,2810931,Como-foi-a-troca-de-roupas-rapida-da-comissao-de-frenteda-Unidos-da-Tijuca.html> Acesso em: 11 mai. 2019.

COMISSÃO DE FRENTE. Disponível em: <http://comissaodefrente.blogspot. com/2012/07/nossa-historia-unidos-da-tijuca-e-as.html> Acesso em: 17 dez. 2018.

DICIONÁRIO ONLINE DE PORTUGUÊS. Hibridismo. Disponível em: <https:// www.dicio.com.br/hibridismo/> Acesso em: 19 dez. 2018.

ESO EM FOCO. Espírito Santo/RN 51 Anos - Fotos Antigas. Disponível em: $<$ https://espiritosantornemfoco.wordpress.com/2013/01/03/espirito-santorn-50anos-fotos-ii/> Acesso em: 21 dez. 2018.

FERREIRA, Aurélio Buarque de Holanda. Mini Aurélio: o dicionário da língua portuguesa. $8^{\text {a }}$. ed. ver. atual. - Curitiba: Positivo, 2010.

GIDDENS, Anthony. O mundo em descontrole. Tradução de Maria Luiza X. de A. Borges - Rio de Janeiro: Record, 2000.

GIFFONI, Maria Amália Corrêa. A dança folclórica brasileira. São Paulo: Melhoramentos, 1964.

VOL. 16 |N. 1 | JUN. 2019 ISSN 1415-7950

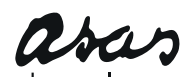

da palavra 
INSTAGRAM. Unidos em Asa Branca. Disponível em: < https://www.instagram. $\mathrm{com} / \mathrm{p} / \mathrm{BjwLE} 9 \mathrm{EHG} 4 \mathrm{E} /$ ?utm_source=ig_share_sheet\&igshid=pizg3ppdu7hg $>$ Acesso em: 23 dez. 2018.

MARTÍN-BARBERO, Jesús; REY, Germán. Os Exercícios do ver - Hegemonia do audiovisual e ficção televisiva. Tradução de Jacob Gorender. São Paulo: SENAC, 2001.

MINTZ, Sidney W. Cultura: uma visão antropológica. Trad. de James Emanuel de Albuquerque. Disponível em: <http://www.scielo.br/pdf/tem/v14n28/a10v1428.pdf> Acesso em: 19 dez. 2018.

MONTE ALEGRE EM DIA. Ginásio lotado na penúltima noite de apresentações do festival de quadrilhas juninas. Disponível em: $<$ http://montealegreemdia.blogspot. com/2015/06/ginasio-lotado-na-penultima-noite-de.html> Acesso em: 21 dez. 2018.

PRODANOV, Cleber Cristiano; FREITAS, Ernani Cesar de. Metodologia do Trabalho Científico [recurso eletrônico]: métodos e técnicas da pesquisa e do trabalho acadêmico. 2. ed. Novo Hamburgo: Feevale, 2013. 277 p. Disponível em: http://<www.feevale.br/Comum/midias/8807f05a-14d0-4d5b-b1ad-1538f3aef538/Ebook\%20Metodologia $\% 20 \mathrm{do} \% 20$ Trabalho\%20Cientifico.pdf> Acesso em: $17 \mathrm{dez}$. 2018.

SANTOS, Eliseu Ramos dos. A cultura popular e as quadrilhas juninas. Revista Desenredos - ISSN: 2175-3903, ano IV, n. 14, Teresina - Piauí - julho, agosto, setembro de 2012. Disponível em: <http://desenredos.dominiotemporario.com/ doc/14-Ensaio-Eliseu-Quadrilhas.pdf> Acesso em: 15 dez. 2018.

SILVA, Daniel da Rocha. Meu "Xamego", "Maracangaia", "Arryba" saia: que linguagem é essa? Revista Espirales, ISSN: 2594-9721, v. 1, n. 2, março/agosto de 2018. Disponível em: <https://revistas.unila.edu.br/espirales/article/view/1323/1164> Acesso em: 18 dez. 2018.

SILVA, Priscila Santos. Vida de quadrilheiro: notas etnográficas dos bastidores da Quadrilha Junina Século XX - Aracaju - SE. Seminário de Estudos Culturais, Identidades e Relações Interétnicas, Universidade Federal de Sergipe, São Cristóvão, Dias 05, 06 E 07 De agosto de 2009. Disponível em: <http://docplayer.com. br/28678984-Vida-de-quadrilheiro-notas-etnograficasdos-bastidores-da-quadrilhajunina-seculo-xx-aracaju-se.html> Acesso em: 13 mar. 2018.

UNIDOS EM ASA BRANCA 2015 FINAL LEVANTA POEIRA. Disponível em: $<$ https://www.youtube.com/watch?v=XZQpq4fuyOU> Acesso em: 23 dez. 2018.

Daniel da Rocha SILVA

Graduado em Letras (Faculdades Integradas de Sergipe - FISE); Pós-graduado em Educação Especial e Inclusiva (Faculdade Jardins); Tobias Barreto -SE. E-mail: danieldarochasilva@gmail.com 